\title{
Antioxidant, anti-inflammatory and anti-apoptotic effects of crocin against doxorubicin-induced myocardial toxicity in rats
}

Sara Asaad ABDULKAREEM ALJUMAILY

Karabük Üniversitesi Tip Fakültesi: Karabuk Universitesi Tip Fakultesi

Mehmet Demir

Karabük Üniversitesi Tip Fakültesi: Karabuk Universitesi Tip Fakultesi

Hulya Elbe

Mugla Sitki Kocman Universitesi Tip Fakultesi

Gurkan Yigitturk

Mugla Sitki Kocman Universitesi Tip Fakultesi

Yasemin Bicer

Karabuk Universitesi Tip Fakultesi

Eyup Altinoz ( $\nabla$ eyupaltinoz@karabuk.edu.tr)

Karabuk Universitesi Tip Fakultesi https://orcid.org/0000-0002-3991-9773

\section{Research Article}

Keywords: Doxorubicin, crocin, apoptosis, oxidative stress, myocardial toxicity

Posted Date: May 11th, 2021

DOI: https://doi.org/10.21203/rs.3.rs-418902/v1

License: () (1) This work is licensed under a Creative Commons Attribution 4.0 International License.

Read Full License

Version of Record: A version of this preprint was published at Environmental Science and Pollution Research on July 28th, 2021. See the published version at https://doi.org/10.1007/s11356-021-15409-w. 


\section{Abstract}

Doxorubicin (DOX) is a well-known chemotherapeutic drug for most malgnencies including breast cancer and leukemia whilst the usage of DOX is limited owing to its cardiotoxicity. The present study analyzed the effects of crocin on doxorubicin's cardiotoxic efect in rat myocardium and searched their mechanistic interaction in the pathogenesis of DOX-induced myocardial toxicity. Forty rats were divided into four groups; (a) control (received normal saline as a dose of $1 \mathrm{ml} / \mathrm{kg}$ by ip for 15 days), (b) Crocin (received crocin as a dose of $40 \mathrm{mg} / \mathrm{kg} / 24 \mathrm{~h}$ by ip for 15 days), (c) DOX (received DOX as a dose of $2 \mathrm{mg} / \mathrm{kg} / 48 \mathrm{~h}$ by ip in six injection, cumulative dose $12 \mathrm{mg} / \mathrm{kg}$ ), and (d) DOX + Crocin (received DOX as a dose of 2 $\mathrm{mg} / \mathrm{kg} / 48 \mathrm{~h}$ by ip in six injection and crocin as a dose of $40 \mathrm{mg} / \mathrm{kg} / 24 \mathrm{~h}$ ip for 15 days). According to the present study, DOX administration caused significant increases in lipid indices (triglyseride, low-dencity lipoproteins and very low-dencity lipoproteins) as well as cardiac markers (Creatine kinase-muscle/brain and Cardiac Troponin I). Morever, DOX caused significant increases in oxidative stress parameters (malondialdehyde and total oxidant status) as well as decreases in antioxidant defense systems (glutathione, superoxide dismutase, catalase and total antioxidant status). The present study also demonstrated that co-administration of crocin with DOX significantly ameliorated the lipid profile and biochemical parameters in rats receiving DOX. The results were supported by histopathological and immunohistochemical evaluations. Taken together, our results reveal that crocin might be a cardioprotective agent in DOX treated patients for cancer.

\section{Introduction}

Doxorubicin (DOX), one of the anthracycline glicoside antibiotic, is a frequently used as a chemotherapeutic drug owing to treat several malignancies in patients, such as breast cancer, leukemia, and sarcoma by causing DNA intercalation and inhibiting the DNA replication (Migrino et al. 2008, Swain et al. 2003). The chief adverse effect of DOX treatment is dose depended cardiotoxicty that is a limiting factor for clinical usage of the drug during long-term administration in anticancer therapy (Hong et al. 2002). Although the main mechanism of cardiotoxicity caused by DOX-induced toxicity is unknown, DOX raises inflammation and oxidative stress in heart tissue including lipid peroxidation, mitochondrial DNA damage, apoptosis as well as deteriorate calcium homeostasis (Li et al. 2016, Octavia et al. 2012).

Increased both calcium and reactive oxygen species (ROS) in mitochondria leads to generate lipid peroxidation and the formation of oxidative injury and cell membran of cardiyomyocytes (Zhou et al. 2001a). Also, an increase oxidative stress which raised after DOX treatment contributes to the activation of apoptotic signaling pathways and leads to apoptotic cell death of myocytes (Octavia et al. 2012). It seems that myocardial infarction, heart failure and cardiac dysfunction are associated with myocardial apoptosis (Abbate et al. 2006, Takemura et al. 2013). Due to the high effectiveness of DOX as a chemotherapeutic drug in many cancers, recent studies are associated with preventing and treating its adverse cardiac effects of DOX by using phytochemicals or drug along with DOX (Abushouk et al. 2017, Durdagi et al., Oner et al. 2019). 
In traditional medicine, saffron (Crocus sativus L.) has been used for a long time as carminative, tonic, expectorant, and sedative (Mousavi et al. 2010). Also, it is reported that saffron is used to treat for several deseases including cardiovascular disorders, urological infections and, asthma (Tavakkol-Afshari et al. 2008). Crocin, one of the most common bioactive constituents of saffron, has many pharmacological properties, such as antioxidant, free radical scavenger (Mousavi et al. 2010), anti-cancer (Festuccia et al. 2014), anti-inflammatory (Hong \&Yang 2013), antiatherosclerotic and cardioprotective effects (Farkhondeh \&Samarghandian 2014). The structure of crocin, water-soluble carotenoid pigment, is mono and diglycosyl esters of a polyene dicarboxylic acid, named crocetin and responsible for the red color of saffron (Thushara et al. 2013). Some studies have reported that cardioprotective effects of crocin are associated with regulation of antioxidant enzymatic activities and cardiac markers (Hariri et al. 2010, Shen \&Qian 2006). It has shown that crocin protects for cardiyomyocytes against hypoxic damage by increasing the level of vascular endothelial growth factor (VEGF), which is an angiogenic protein (Wu et al. 2010).

Here, we aimed to assess the possible effecs of crocin combined with DOX on cardiotoxicity, and the possible role of pathogenesis of DOX-induced cardiotoxicity, based on the spesifik cardiac biomarkers, biochemical parameters, oxidative stress markers, histopatological and immunohistochemical evaluations in Wistar albino rats.

\section{Materials And Methods}

\section{Animals}

Forty healty adult male Wistar albino rats (10 weeks age, $225+25 \mathrm{~g}$ ) were purchased from Zonguldak Bulent Ecevit University Faculty of Medicine Experimental Animal Production and Research Center (ZBEUN-DEHAM). All rats were housed in well wentilated room with temperature- and humidity-controlled conditions (an ambient temperature range of $22^{\circ} \mathrm{C}$; relative humidity of $55-60 \%$ ) in rat cages with a 12 h-12 h light-dark cycle (light from 08: 00-20: 00). The study was approved by the Experimental Animals Ethics Committee of Zonguldak Bulent Ecevit University, Faculty of Medicine (Protocol No: 2020/04). All experimental procedures were carried out in accordance with the Animal Ethics Committee Guidelines for the use of experimental animals. The experimental animals were allowed access to drinking water and standard rodent diet ad libitum.

\section{Study design}

DOX (Doxorubicin® $10 \mathrm{mg}$ ) was purchased from Kocak Company (Istanbul, TURKEY) and crocin was obtained from Sigma Aldrich Corporation (St. Louis, Missouri, ABD). Forty Wistar rats were randomly aliquoted into four groups. At the beginning of the study, each experimental group consisted of ten animals. The first group (control): Animals recevied normal saline $(1 \mathrm{ml} / \mathrm{kg})$ via intraperitoneal injection (i.p.) for 15 days. The second group (Crocin): Animals received crocin $(40 \mathrm{mg} / \mathrm{kg})$ via i.p for 15 consecutive days (Razmaraii et al. 2016b). The third group (DOX): Animals received DOX (2 mg/kg) via i.p in six injection at 48 hours intervals during the 12-day period (cumulative dose:12 mg/kg) (Razmaraii 
et al. 2016a). The fourth group (DOX + Crocin): Animals received crocin (40 mg/kg) through 15 consecutive days (starting 4 days before first DOX administration) along with DOX teratment (with the same dose as the group mentioned above). Lyophilized DOX powder was prepared for i.p injection by dissolving with the solvent water. Crocin powder was dissolved by normal saline $(0.9 \%)$. Throughout the study, all applications were carried out everyday in the same time period.

\section{Blood and tissue collection}

At the sixteenth day of the experiment, all rats were anesthetized under ketamine/xylazine anesthesia. Then, the blood samples were taken into non-heparinized tubes from the abdominal vein. Following blood collection, all tubes were kept under room condition about $30 \mathrm{~min}$ for allowing to clot. The serum was obtained by centrifuging at $3000 \mathrm{rpm}$ for $20 \mathrm{~min}$ and stored at $-80^{\circ} \mathrm{C}$ until for determination of biochemical parameters. The rats were then killed by cervical decapitation and the heart tissues were removed immediately. The cardiac tissues were cleaned with ice-cold normal saline to remove excess blood then weighed. The tissues were divided into two equal parts. One of the parts was stored at $-80^{\circ} \mathrm{C}$ until for measurement of biochemical parameters. The other part of cardiac tissue was fixed in $10 \%$ neutral buffered formalin for histological examinations.

\section{Biochemical analysis}

\section{Preparation of samples}

Rat heart tissues were removed from the freezer and rapidly weighed. Then the tissues were homogenized at 10,000 rpm for one minute by an otomatic homogenizer (Bioprep-24 Homogenizer, Hangzhou Allsheng Instruments Co., Ltd., China) in a 10-fold volume ice-cold phosphate buffer (70 mM, $\mathrm{pH}$ 7.5). The homogenate was used for determination of MDA analysis. The homogenates were used for determination of MDA analysis. To obtain supernatant, the homogenates were centrifuged at $+4^{\circ} \mathrm{C}$ and $3000 \mathrm{rpm}$ for ten minutes. The supernatants were used for determination of tissue biochemical parameters.

\section{Assessment of oxidative stress markers}

Heart tissue homogenate was used for assessment of lipid peroxidation by measuring cardiac MDA levels according to the method of Ohkawa et al. (Ohkawa et al. 1979). Heart tissue supernatants were used for the determination of the antioxidant enzyme activities. Cardiac superoxide dismutase (SOD) activity was determined with the method proposed by Sun et al. (Sun et al. 1988), and cardiac catalase (CAT) activity was determined by the method of Aebi (Aebi 1974). Reduced glutathione (GSH) content, one of the non-enzymatic antioxidant markers, was determined with the method illustrated by Ellman (Ellman 1959). Cardiac protein content was assessed according to the Biuret method (Gornall et al. 1949) using bovine serum albumin (BSA) as standard and used for calculating the antixiadant enzyme's activities. Total antioxidant status (TAS) of cardiac tissue was determined with the method proposed by Erel (Erel 2004). TAS content was studied according to the the manufacturer's instructions (Rel Assay Diagnostics, Gaziantep, TURKEY). Total oxidant status (TOS) of cardiac tissue was measured according 
to the method of Erel (Erel 2005). TOS content was studied according to the manufacturer's instructions (Rel Assay Diagnostics, Gaziantep, TURKEY).

\section{Assessment of cardiomyocytes damage}

The stored serum samples were removed from freezer and kept under room condition for bring all samples to room temperature before use. The serum content of cardiac isoenzyme creatine kinase (CK$\mathrm{MB}$ ) and cardiac troponin I (cTn-I) were measured by using their respective ELISA kits spesific for rats, according to the principle of kits (Elabscience, USA; Catalog number: E-EL-R1327 and E-EL-R1253, respectively).

\section{Assessment of lipid profile}

The serum content of lipid profile, including triglyceride, high-density lipoprotein (HDL), low-density lipoprotein (LDL) and very low-density lipoprotein (VLDL) were assessed by using their commercially available Architect c 1600 automatic analyzer kits by Abbott Laboratories (Illinois, USA).

\section{Histological analysis}

\section{Histopathological evaluation}

The heart tissues were fixed in $10 \%$ neutral buffered formalin for $48 \mathrm{~h}$. Tissues were washed in running water, and were dehydrated with increasing concentrations of ethanol (50\%, 75\%, 96\% and 100\%). After dehydration, specimens were placed into xylene to obtain transparency and were embedded in paraffin. Paraffin blocks were cut at $5 \mu \mathrm{m}$, mounted on slides, stained with hematoxylin and eosin ( $\mathrm{H}-\mathrm{E})$. The tissue sections were examined under light microscopy. The evaluated parameters for severity of cardiac damage were congestion, necrosis, infiltration and loss of myofibrillar in 10 different fields for each section. For this analysis, cardiac damage was semiquantitatively graded as absent (0), mild (1), moderate (2), and severe (3), for each criterion. The maximum damage score was 12 . All sections were examined using a Nikon Eclipse 80i light microscope and Nikon Image Analysis system.

\section{Immunohistochemical (IHC) evaluation}

For immunohistochemical analysis, sections were mounted on polylysine coated slides. After rehydrating, samples were transferred to citrate buffer $(\mathrm{pH}$ 7.6) and heated in a microwave oven for 20 minutes. After cooling for 20 minutes at room temperature, the sections were washed with phosphate buffered saline (PBS). Then sections were kept in $0.3 \% \mathrm{H}_{2} \mathrm{O}_{2}$ for 7 minutes and afterward washed with PBS. Sections were incubated with at an anti-TNFa (1:100, bs-2081R, Bioss, China) and anti-Caspase 3 (1:100, bs0081R, Bioss, China) for 60 minutes. They then were rinsed in PBS and incubated with biotinylated goat antipolyvalent for 10 minutes and streptavidin peroxidase (SHP 125, ScyTek Laboratories, ABD) for 10 minutes at room temperature. Staining was completed with chromogen + substrate for 15 minutes, and slides were counterstained with Mayer's hematoxylin (M06002, Bio-optica, ITALY) for 1 minute, rinsed in tap water, and dehydrated. The antibody was used according to the manufacturer's instructions. Staining for anti-TNFa and anti-caspase-3 was identified by a brown color. The relative intensity of TNFa and 
caspase-3 immunostaining was scored as follows: 0-5\% (+), 6-20\% (++), 21-40\% (+++), 41-60\% (++++), 61-80\% (+++++), and 81-100\% (++++++). All sections were examined using a Nikon Eclipse 80i light microscope and Nikon Image Analysis system.

\section{Statistical Analysis}

Statistical analysis was carried out using the SPSS for Windows version 14.0 (SPSS Inc., Chicago, III., USA) statistical program. All data are expressed as arithmetic mean \pm SE. Normality for continued variables in groups were determined by the Shapiro Wilk test. The variables didn't show normal distribution $(p<0.05)$. Kruskal-Wallis and Mann-Whitney $U$ tests were used for comparison of variables among the studied groups. $p<0.05$ was regarded as significant.

\section{Results}

\section{Effects of crocin on cardiac oxidative stress markers and antioxidant parameters}

The Table 1 and the Table 2 present the average cardiac oxidative stress markers and tissue antioxidant contents. The values of cardiac MDA, antioxidant enzymes (SOD, CAT), GSH, TAS, and TOS were analyzed statistically. The levels of cardiac oxidative stress markers and tissue antioxidant contents showed no pathological changes between control and crocin groups. Statistical analysis showed that DOX treatment resulted in dramatically increases $(p<0.001)$ in the cardiac levels of MDA and TOS relative to values measured within the control group. In addition, rats receiving DOX also revealed significant reductions $(p<0.001)$ in cardiac GSH, TAS levels as well as the activities of antioxidant enzymes CAT and SOD as compared to levels measured within the control group. In contrast, the rats receiving DOX with crocin reversed significantly the effect of DOX administration on cardiac oxidative stress markers (MDA and TOS) $(p<0.001)$ as compared to the DOX group. Similarly, treatment of DOXintoxicated rats with crocin revealed significant increases in both antioxidant contents (GSH and TAS) ( $p$ $<0.001)$ and the activities of antioxidant enzymes (CAT and SOD) $(p<0.001)$ relative to values measured within the DOX group. 
Table 1

Comparison of average tissue oxidant-antioxidant parameters

\begin{tabular}{|lllll|}
\hline GROUPS & $\begin{array}{l}\text { MDA } \\
\text { (nmol/g wet } \\
\text { tissue) }\end{array}$ & $\begin{array}{l}\text { GSH } \\
\text { (nmol/g wet } \\
\text { tissue) }\end{array}$ & $\begin{array}{l}\text { SOD (U/g } \\
\text { protein) }\end{array}$ & $\begin{array}{l}\text { CAT } \\
\text { (K/g } \\
\text { protein) }\end{array}$ \\
\hline Group 1: Control & $395.36 \pm 26.88$ & $483.50 \pm 1.99$ & $80.79 \pm 3.06$ & $8.46 \pm 0.45$ \\
\hline Group 2: Crocin & $290.39 \pm 33.03$ & $506.80 \pm 5.70$ & $87.97 \pm 3.96$ & $11.10 \pm 1.00$ \\
\hline Group 3: DOX & $1405.42 \pm 226.30^{\mathrm{a}}$ & $229.41 \pm 14.79^{\mathrm{a}}$ & $38.00 \pm 2.00^{\mathrm{a}}$ & $4.38 \pm 0.36^{\mathrm{a}}$ \\
\hline $\begin{array}{l}\text { Group 4: } \mathrm{DOX}+ \\
\text { Crocin }\end{array}$ & $495.10 \pm 5.91^{\mathrm{b}}$ & $345.28 \pm 13.78^{\mathrm{b}}$ & $57.62 \pm 3.05^{\mathrm{b}}$ & $7.09 \pm$ \\
\hline Data are expressed as the arithmetic mean $\pm \mathrm{SE}(\mathrm{n}=10)$. & & $0.62^{\mathrm{c}, \mathrm{d}}$ \\
\hline a $\mathrm{p}<0.001$ group 3 vs group 1 ve group 2 ${ }^{\mathrm{b}} \mathrm{p}<0.001$ group 4 vs group 2 and group 3 & \\
\hline${ }^{\mathrm{c}} \mathrm{p}<0.005$ group 4 vs group 2 ${ }^{\mathrm{d}} \mathrm{p}<0.001$ group 4 vs group 3 & & \\
\hline
\end{tabular}

Table 2

Comparison of average tissue TAS and TOS values.

\begin{tabular}{|lll|}
\hline GROUPS & $\begin{array}{l}\text { TAS } \\
(\mathbf{m m o l} \text { Trolox eqv/L) }\end{array}$ & $\begin{array}{l}\text { TOS } \\
(\mu \mathrm{mol} \mathrm{H202} \mathrm{Equiv.} / \mathrm{L})\end{array}$ \\
\hline Group 1: Control & $1.27 \pm 0.09$ & $7.48 \pm 0.22$ \\
\hline Group 2: Crocin & $1.52 \pm 0.09$ & $7.06 \pm 0.14$ \\
\hline Group 3: DOX & $0.67 \pm 08.08^{\mathrm{a}}$ & $10.91 \pm 0.65^{\mathrm{a}}$ \\
\hline Group 4: DOX + Crocin & $1.20 \pm 0.17^{\mathrm{b}, \mathrm{c}}$ & $7.33 \pm 0.26^{\mathrm{c}}$ \\
\hline Data are expressed as the arithmetic mean $\pm \mathrm{SE}(\mathrm{n}=10)$. & \\
\hline \begin{tabular}{l} 
a $\mathrm{p}<0.001$ group 3 vs group 1 and group $2{ }^{\mathrm{b}} \mathrm{p}<0.05$ group 4 vs group $2{ }^{\mathrm{c}} \mathrm{p}<0.001$ group 4 vs group \\
\hline
\end{tabular} \\
\hline
\end{tabular}

\section{Effects of crocin on cardiotoxicity induces}

The Table 3 presents the comparison of mean serum cardiac CK-MB and Troponin I values. The serum cardiotoxicity markers showed no pathological changes in the control and crocin groups. The data revealed that the levels of the serum cardiotoxicity indices (CK-MB and cTnl) dramatically increased ( $p<$ 0.001) after DOX treatment relative to values measured within their control ones (control and crocin groups). On the other hand, the rats receiving DOX with crocin reversed significantly the effect of DOX treatment on cardiotoxicity indices CK-MB $(p<0.005)$ and $c T n I(p<0.001)$ as compared to the DOX group. 
On the other hand, the rats receiving crocin with DOX reversed significantly the effect of DOX treatment on cardiotoxicity indices ( $p<0.005$ for CK-MB; $p<0.001$ for $c T n l)$ as compared to the DOX group.

Table 3

Comparison of mean serum CK-MB and cardiac Troponin I values

\begin{tabular}{|lll|}
\hline GROUPS & $\begin{array}{l}\text { CK-MB } \\
(\mathbf{p g} / \mathbf{m l})\end{array}$ & $\begin{array}{l}\text { Troponin I } \\
(\mathbf{p g} / \mathbf{m l})\end{array}$ \\
\hline Group 1: Control & $16.62 \pm 1.67$ & $175.50 \pm 17.58$ \\
\hline Group 2: Crocin & $15.76 \pm 1.32$ & $186.16 \pm 12.02$ \\
\hline Group 3: DOX & $32.36 \pm 2.15^{\mathrm{a}}$ & $354.89 \pm 16.20^{\mathrm{a}}$ \\
\hline Group 4: DOX + Crocin & $20.80 \pm 0.66^{\mathrm{b}, \mathrm{c}}$ & $231.96 \pm 7.85^{\mathrm{b}, \mathrm{c}}$ \\
\hline Data are expressed as the arithmetic mean $\pm \mathrm{SE}(\mathrm{n}=10)$. & \\
\hline $\begin{array}{l}\text { a } \mathrm{p}<0.001 \text { group } 3 \text { vs group } 1 \text { and group } 2{ }^{\mathrm{b}} \mathrm{p}<0.005 \text { group } 4 \text { vs group } 2{ }^{\mathrm{c}} \mathrm{p}<0.001 \text { group } 4 \text { vs group } \\
\text { 3. }\end{array}$ & \\
\hline Effects of Crocin On lipid $\mathbf{p r o f i l e ~}$ & \\
\hline
\end{tabular}

The Table 4 presents the comparison of mean serum lipid parameters. The data demonstrated that rats receiving DOX revealed significant increases in serum TG and LDL levels $(p<0.001)$ as well as VLDL levels $(p<0.005)$ compared to the control group. In contrast, the rats receiving DOX revealed significant reduction in serum HDL levels $(p<0.001)$ relative to values measured within the control group. On the other hand, rats receiving DOX with crocin decreased in serum TG and VLDL levels $(p<0.001)$ as well as LDL $(p<0.005)$ as compared to the DOX group. In addtion, treatment of rats receiving DOX with crocin ameliorated serum HDL levels $(p<0.005)$ relative to the DOX group. 
Table 4

Comparison of mean serum lipid parameters

\begin{tabular}{|c|c|c|c|c|}
\hline GROUPS & TG (mg/dl) & VLDL(mg/dl) & HDL (mg/dl) & LDL (mg/dl) \\
\hline Group 1: Control & $55.40 \pm 3.44$ & $10.40 \pm 0.44$ & $45.82 \pm 2.05$ & $8.31 \pm 0.85$ \\
\hline Group 2: Crocin & $41.50 \pm 1.98^{a}$ & $8.21 \pm 0.33^{\mathrm{a}}$ & $50.96 \pm 2.68$ & $7.22 \pm 0.67$ \\
\hline Group 3: DOX & $88.40 \pm 5.17^{b, c}$ & $16.50 \pm 1.35^{\mathrm{e}, \mathrm{c}}$ & $37.40 \pm 1.67^{f, c}$ & $16.06 \pm 1.04^{b, c}$ \\
\hline Group 4: DOX + Crocin & $49.70 \pm 4.21^{d}$ & $10.04 \pm 0.84^{d}$ & $44.46 \pm 1.95^{\mathrm{g}}$ & $12.46 \pm 0.92^{h, j, g}$ \\
\hline \multicolumn{5}{|c|}{ Data are expressed as the arithmetic mean \pm SE $(n=10)$. } \\
\hline \multicolumn{5}{|c|}{ a $p<0.005$ group 2 vs group $1^{b} p<0.001$ group 3 vs group $1^{c} p<0.001$ group 3 vs group 2} \\
\hline \multicolumn{5}{|c|}{${ }^{d} p<0.001$ group 4 vs group $3{ }^{e} p<0.005$ group 3 vs group $1{ }^{f} p<0.01$ group 3 vs group 1} \\
\hline \multicolumn{5}{|c|}{$\mathrm{g} p<0.05$ group 4 vs group $3{ }^{\mathrm{h}} \mathrm{p}<0.005$ group 4 vs group $1{ }^{\mathrm{j}} \mathrm{p}<0.001$ group 4 vs group 2} \\
\hline
\end{tabular}

\section{Histopathological findings}

The group 1 (control) and group 2 (crocin) groups were normal in histological appearance (Figs. 1a, b). There was no significant difference among these groups $(p>0.05)$. Congestion, necrotic cells with picnotic nuclei, inflammatory cell infiltration, loss of myofibrillar and cytoplasmic vacuolization were detected in DOX group (Figs. 1c, d, e). The mean histopathological damage score (MHDS) was $6.30 \pm$ 0.42 DOX group. Statistically significant increase in MHDS was found in the DOX group, when compared to the group 1 and 2 ( $p<0.001$, for all). The histopathological changes markedly regressed in DOX + Crocin group (Fig. 1f). The MHDS was $2.10 \pm 0.27$ DOX + Crocin group. When DOX group and DOX + Crocin group were compared, statistically significant difference was detected $(p<0.001)$. The mean histopathological damage score for each group was given in Table 5.

Table 5

Average histopathological damage score (MHDS)

\begin{tabular}{|ll|}
\hline Groups & Histopathological damage score \\
\hline Group 1: Control & $0.30 \pm 0.15$ \\
\hline Group 2: Crocin & $0.50 \pm 0.16$ \\
\hline Group 3: DOX & $6.30 \pm 0.42^{\mathrm{a}}$ \\
\hline Group 4: DOX + Crocin & $2.10 \pm 0.27^{\mathrm{a}, \mathrm{b}}$ \\
\hline Data are expressed as the arithmetic mean $\pm \mathrm{SE}(\mathrm{n}=10)$. \\
\hline a $p<0.001$ vs group 1 and group $2^{\mathrm{b}} \mathrm{p}<0.001$ vs group 3 \\
\hline
\end{tabular}




\section{Immunohistochemical findings}

TNF-a expression in the heart tissues of the experimental groups was observed in the sarcoplasm, nuclei and capillary vessels of cardiomyocytes. TNF-a expression is weak $(0-5 \%)$ in group 1 and 2 . TNF-a expression is quite high in the DOX group (81-100\%). In the DOX + Crocin group, it is seen that the expression is moderate (41-60\%) (Fig. 2).

It was observed that the expression of caspase 3 in the heart tissues of the experimental groups was found in the sarcoplasm of cardiomyocytes and the tunica media layer (smooth muscles) of the vessels. Caspase 3 expression is weak ( $0-5 \%)$ in group 1 and 2. In the DOX group, caspase 3 expression was moderate (41-60\%). In the DOX + Crocin group, it is seen that the expression is moderate to low (2140\%) (Fig. 3). The TNFa and caspase-3 immunoreactivity scores are shown in Table 6

Table 6

TNF- $a$ and caspase 3 immunoreactivity

\begin{tabular}{|lllll|}
\hline İmmunoreactivity & Control Group & Crocin Group & DOX Group & DOX + Crocin Group \\
\hline TNF-a & + & + & ++++++ & +++ \\
Caspas 3 & + & + & +++ & ++ \\
\hline $\begin{array}{l}0-5 \%=\text { score }(+) ; 6-20 \%=\text { score }(++) ; 21-40 \%=\text { score }(+++) ; 41-60 \%=\text { score }(++++) ; 61-80 \%= \\
\text { score }(+++++) ; \text { and } 81-100 \%=\text { score }(++++++)\end{array}$ & & \\
\hline
\end{tabular}

\section{Discussion}

In the current study, we administered the cumulative dose of DOX $(12 \mathrm{mg} / \mathrm{kg})$ to observe cardiotoxicity during 2 weeks in line with previous studies (Babaei et al. 2020, Razmaraii et al. 2016c). The dose of DOX is the same as using in treatment of human cancers (Tarr et al. 2015). Based on previous evidence, DOXinduced cardiotoxicity is associated with dose-related and long-term administration of DOX (Takemura \&Fujiwara 2007). To our knowledge, the main mechanism of cardiotoxicity caused by DOX administration hasn't been exactly known yet. However, many researchers examining doxorubicin's cardiotoxic efects have reported that the overproduction of ROS (Ahmed et al. 2005, Berthiaume \&Wallace 2007) and the stimulation of inflammation (Deepa \&Varalakshmi 2005) are responsible for DOX-induced adverse effects on myocardium. Owing to its lower antioxidant capacity in myocardium, heart tissue is thought to be the main target tissue for dox-induced oxidative damage relative to other tissues (De Beer et al. 2001, Zhou et al. 2001b). Also, myocardium contains cardiolipin, which is considered to have an attractive for DOX, resulting in DOX accumulation in the heart mitochondria, disturbance of the respiratory chain, and stimulation of apoptotic pathways (Ascensão et al. 2005).

The formation of ROS and cardiac oxidative stress have been demostrated in Wistar rats receiving DOX (Oner et al. 2019). The increase in ROS production with DOX administration results in oxidative stress and is one of the major causes of myocardial damage (Berthiaume \&Wallace 2007). In view of these facts, 
researchers have suggested trials on antioxidant therapy on DOX-induced toxicity. Antioxidants ameliorate DOX-caused oxidative damage by scavenging free radicals and the regulation of the activities of antioxidant enzymes without inhibiting DOX's anticancer properties. According to all these evidence, we studied the cardioprotective effects of crocin by evaluating biochemical, histopathological, and immunohistochemical analyses.

Previous studies have reported that several antioxidants including coenzyme Q, N-acetylcysteine, vitamin $\mathrm{E}$ and vitamin $\mathrm{C}$ have cardioprotective activities to prevent myocardial damage indueced by antracyclines in animals (Songbo et al. 2019, Zamorano et al. 2016). Recently, several studies have demonstrated that crocin can be used as a new therapeutic drug, owing to its anticancer (Fernández 2006, Konoshima et al. 1998) and antioxidant properties (Assimopoulou et al. 2005, Hosseinzadeh et al. 2005). Whereas the mechanism of crocin, a water soluble carotenoid of saffron, is not yet fully established, but it has been recognized that the effect of crocin on pathways may be similar to well known carotenoids (Pham et al. 2000). Therefore, it has been accepted that crocin is able to ameliorate intracellular oxidative stress by increasing the activities of the antioxidant enzymes (Rahaiee et al. 2015).

MDA, one of the end product of lipid peroxidation, is an indicator of oxidative stress induced by free radicals. DOX causes to increase ROS, impairs membrane function and exposes cardiac dysfunction via myocardial apoptosis. Elevations in the levels of lipid peroxidation of heart tissue by increasing MDA and TOS levels following DOX administration were determined in the present study. In addition, coadministration of crocin with DOX resulted in significant amelioration of DOX-induced lipid peroxidation in rat myocardium. Protection of the heart by strengthening the cardiac antioxidant defense system against DOX-induced cardiac injury caused by ROS formation plays an important role in protection against DOX-induced myocardial damage (Arafa et al. 2014, Oner et al. 2019). Previous studies reported that DOX application caused impairment in antioxidant defense such as SOD, CAT and GSH (Qi et al. 2020, Sadek et al. 2021). As antioxidant enzymes, SOD and CAT scavenge superoxide anion and hydrogen peroxide. GSH, non-enzymatic antioxidant, is a tripeptide formed by the combination of glutamate, cysteine and glycine. GSH cleans ROS from the body with its powerful antioxidant properties. Our data suggested that the activities of cardiac SOD and CAT as well as the levels of TAS and GSH remarkably decreased in heart tissue of rats receiving DOX. Our data also revealed that co-administration of crocin with DOX ameliorated antioxidant defense including SOD, CAT, GSH and TAS. As a potent antioxidant, crocin shows its possible mechanism by directly scavenging ROS (Hosseinzadeh et al. 2005) and up-regulating antioxidant enzyme genes (Deng et al. 2018). In line with our findings, previous studies showed that crocin elevates the antioxidant capacity in cardiac tissue in different conditions such as isoprenaline-induced myocardial fibrosis and arsenic trioxide-induced cardiotoxicity (Chu et al. 2020, Liang et al. 2020). Also Chu et al (Chu et al. 2020) have demonstrated that crocin ameliorates increased ROS levels induced by DOX in H9c2 cells.

It is well known that DOX administration causes imbalance on the serum lipid and fatty acid profiles (Hong et al. 2002). Hyperlipidemia induced by DOX leads harmful effects on heart function and is one of the most known reason for DOX-induced cardiotoxicity. Therefore, agents with lipid lowering properties 
might have beneficial effects on DOX-induced cardiac damage (Iliskovic \&Singal 1997). Recent studies have shown the evidence that crocin have protective effects against cardiovascular-related disorders including atherosclerosis, hiperlipidemia and cardiac dysfunction (Alavizadeh \&Hosseinzadeh 2014, Li et al. 2018). In this study, we observed increases in triglyceride, LDL and VLDL levels and as well as decrease in HDL levels. On the other hand, co-administration of crocin with DOX resulted in a significant improvement in serum lipid profiles. Based on these results, heart damage caused by DOX induction is associated with increases in the serum lipid profile and crocin might occur its cardioprotective effect by improving these biochemical indices because of its anti-hyperlipidemic properties. In line with our findings, Li et al (Li et al. 2018) reported that crocin decreased total cholesterol, triglyceride and LDL, and increased HDL in a coronary atherosclerosis rat model. Also, Haybar et al (Haybar et al. 2019) demonstrated that DOX administration caused to increase in total cholesterol, TG and LDL, and decreased in HDL whilst gemfibrozil improved the lipid panel in DOX- treated rats.

Normally, CK-MB, and cTnl are located in the cytoplasm of cardiomyocytes and pass through cardiomyocytes into the systemic circulation following cell membrane injury (Goudarzi et al. 2018). Thus, CK-MB and CTnl are cardiac markers and accepted as an indicator to evaluate cardiac dysfunctions. In our study, DOX-induced myocardial toxicity by the formation of ROS caused to elevate these cardiac markers whilst co-administration of crocin with DOX resulted in a significant improvement in elevated cardiac biomarkers. There is an evidence showing that crocin exhibits cardioprotective impact by decreasing serum cardiac markers (Elsherbiny et al. 2016). According to previous study, DOX-induced myocardial toxicity is associated with oxidative stress (Oner et al. 2019). It is well established that crocin could be potent antioxidat agent through down-regulation of apoptotic and inflammatory pathways and/or scavenging free radicals (Elsherbiny et al. 2016).

On the other hand, the evidence suggested that the other mechanisms in the pathogenesis of DOXinduced cardiotoxicity except oxidative stress involve apoptosis and inflammation (Sun et al. 2016). In compliance with previous studies, our results demonstrated significant increases in caspase- 3 and tumor necrosis factor alpha (TNF-a) reactivities in myocardium after DOX injection (Dash et al. 2015, Ma et al. 2019). Also, Shaker et al (Shaker et al. 2018) reported that DOX administration caused to increase in inflammatory markers such as TNF- $\alpha$ and interleukin-1 beta (IL-1 $\beta$ ) and apoptotic markers such as caspase-3. In contrast, our results revealed that increased inflammatory cytokines and apoptotic markers evoked by DOX induction improved by crocin treatment because of its anti-inflammatory and antiapoptotic effectiveness. Moreover, these data are supported by our histopathological evaluation showing improvement in the histological architecture of myocardium through crocin treatment. Consistent with the results of the present study, Razavi et al. (Razavi et al. 2013) showed that crocin might have benefical effects against diazinon-induced cardiotoxicity through regulating signaling pathways associated with oxidative stress and cell apoptosis.

Taken together, present study demonstrated that crocin protected rat myocardium against DOX-induced cardiotoxicity by modulating oxidative stress, reducing apoptosis, and inhibiting hiperlipidemia because of its antioxidant, anti-inflammatory and antihiperlipidemic properties.

Page $12 / 21$ 


\section{Declarations}

Acknowledgments: The research was supported by Karabuk University Scientifict Research Fund (TYL2020-2298).

Ethical Approval and and consent to participate: The study was approved by the Experimental Animals Ethics Committee of Zonguldak Bulent Ecevit University, Faculty of Medicine (Protocol No: 2020/04).

Consent to Publish: Not applicable

Conflict of interest: The authors have declared that there are no conflicts of interest in connection with this article.

Authors Contributions: Sara Asaad ABDULKAREEM ALJUMAILY and Yasemin Bicer studied biochemical analysis, Mehmet Demir designed the study and collected the tissues, Hulya Elbe and Gurkan Yigitturk performed the histological examination of the hearth tissues, Eyup Altınoz designed the study and calculated the biochemical results, and was a major contributor in writing the manuscript.

Availability of data and materials: The datasets used and/or analysed during the current study are available from the corresponding author on reasonable request.

\section{References}

Abbate A, Bussani R, Amin MS, Vetrovec GW, Baldi A (2006): Acute myocardial infarction and heart failure: role of apoptosis. The international journal of biochemistry \& cell biology $38,1834-1840$

Abushouk Al, Ismail A, Salem AMA, Afifi AM, Abdel-Daim MM (2017): Cardioprotective mechanisms of phytochemicals against doxorubicin-induced cardiotoxicity. Biomedicine \& Pharmacotherapy 90, 935-946

Aebi H (1974): Catalase: In: Bergmeyer. Methods in enzymatic analysis Academic Press Inc., New York, $673-686$

Ahmed HH, Mannaa F, Elmegeed GA, Doss SH (2005): Cardioprotective activity of melatonin and its novel synthesized derivatives on doxorubicin-induced cardiotoxicity. Bioorganic \& medicinal chemistry 13 , 1847-1857

Alavizadeh SH, Hosseinzadeh H (2014): Bioactivity assessment and toxicity of crocin: a comprehensive review. Food and Chemical Toxicology 64, 65-80

Arafa MH, Mohammad NS, Atteia HH, Abd-Elaziz HR (2014): Protective effect of resveratrol against doxorubicin-induced cardiac toxicity and fibrosis in male experimental rats. Journal of physiology and biochemistry 70, 701-711 
Ascensão A, Magalhães J, Soares JM, Ferreira R, Neuparth MJ, Marques F, Oliveira PJ, Duarte JA (2005): Moderate endurance training prevents doxorubicin-induced in vivo mitochondriopathy and reduces the development of cardiac apoptosis. American Journal of Physiology-Heart and Circulatory Physiology 289, $\mathrm{H} 722-\mathrm{H} 731$

Assimopoulou A, Sinakos Z, Papageorgiou V (2005): Radical scavenging activity of Crocus sativus L. extract and its bioactive constituents. Phytotherapy Research: An International Journal Devoted to Pharmacological and Toxicological Evaluation of Natural Product Derivatives 19, 997-1000

Babaei H, Razmaraii N, Assadnassab G, Mohajjel Nayebi A, Azarmi Y, Mohammadnejad D, Azami A (2020): Ultrastructural and echocardiographic assessment of chronic doxorubicin-induced cardiotoxicity in rats. Archives of Razi Institute 75, 55-62

Berthiaume J, Wallace KB (2007): Adriamycin-induced oxidative mitochondrial cardiotoxicity. Cell biology and toxicology $23,15-25$

Chu X, Zhang Y, Xue Y, Li Z, Shi J, Wang H, Chu L (2020): Crocin protects against cardiotoxicity induced by doxorubicin through TLR-2/NF-KB signal pathway in vivo and vitro. International immunopharmacology 84, 106548

Dash SK, Chattopadhyay S, Ghosh T, Dash SS, Tripathy S, Das B, Bag BG, Das D, Roy S (2015): Selfassembled betulinic acid protects doxorubicin induced apoptosis followed by reduction of ROS-TNF-acaspase-3 activity. Biomedicine \& Pharmacotherapy 72, 144-157

De Beer EL, Bottone AE, Voest EE (2001): Doxorubicin and mechanical performance of cardiac trabeculae after acute and chronic treatment: a review. European journal of pharmacology 415, 1-11

Deepa P, Varalakshmi P (2005): Biochemical evaluation of the inflammatory changes in cardiac, hepatic and renal tissues of adriamycin-administered rats and the modulatory role of exogenous heparinderivative treatment. Chemico-biological interactions 156, 93-100

Deng M, Li D, Zhang Y, Zhou G, Liu W, Cao Y, Zhang W (2018): Protective effect of crocin on ultraviolet B-induced dermal fibroblast photoaging. Molecular medicine reports 18, 1439-1446

Durdagi G, Pehlivan DY, Oyar EO, Bahceci SA, Ozbek M Effects of Melatonin and Adrenomedullin in Reducing the Cardiotoxic Effects of Doxorubicin in Rats. Cardiovascular Toxicology, 1-11

Ellman GL (1959): Tissue sulfhydryl groups. Archives of biochemistry and biophysics 82, 70-77

Elsherbiny NM, Salama MF, Said E, El-Sherbiny M, Al-Gayyar MM (2016): Crocin protects against doxorubicin-induced myocardial toxicity in rats through down-regulation of inflammatory and apoptic pathways. Chemico-biological interactions 247, 39-48 
Erel O (2004): A novel automated direct measurement method for total antioxidant capacity using a new generation, more stable ABTS radical cation. Clinical biochemistry 37, 277-285

Erel 0 (2005): A new automated colorimetric method for measuring total oxidant status. Clinical biochemistry $38,1103-1111$

Farkhondeh T, Samarghandian S (2014): The effect of saffron (Crocus sativus L.) and its ingredients on the management of diabetes mellitus and dislipidemia. African Journal of Pharmacy and Pharmacology $8,541-549$

Fernández J-A (2006): Anticancer properties of saffron, Crocus sativus Linn. Advances in phytomedicine 2, 313-330

Festuccia C, Mancini A, Gravina GL, Scarsella L, Llorens S, Alonso GL, Tatone C, Di Cesare E, Jannini EA, Lenzi A (2014): Antitumor effects of saffron-derived carotenoids in prostate cancer cell models. BioMed research international 2014

Gornall AG, Bardawill CJ, David MM (1949): Determination of serum proteins by means of the biuret reaction. Journal of biological chemistry $177,751-766$

Goudarzi M, Fatemi I, Siahpoosh A, Sezavar SH, Mansouri E, Mehrzadi S (2018): Protective effect of ellagic acid against sodium arsenite-induced cardio-and hematotoxicity in rats. Cardiovascular toxicology $18,337-345$

Hariri AT, Moallem SA, Mahmoudi M, Memar B, Hosseinzadeh H (2010): Sub-acute effects of diazinon on biochemical indices and specific biomarkers in rats: protective effects of crocin and safranal. Food and chemical toxicology $48,2803-2808$

Haybar H, Goudarzi M, Mehrzadi S, Aminzadeh A, Khodayar MJ, Kalantar M, Fatemi I (2019): Effect of gemfibrozil on cardiotoxicity induced by doxorubicin in male experimental rats. Biomedicine \& Pharmacotherapy $109,530-535$

Hong Y-J, Yang K-S (2013): Anti-inflammatory activities of crocetin derivatives from processed Gardenia jasminoides. Archives of pharmacal research 36, 933-940

Hong YM, Kim HS, Yoon H-R (2002): Serum lipid and fatty acid profiles in adriamycin-treated rats after administration of L-carnitine. Pediatric research 51, 249-255

Hosseinzadeh H, Sadeghnia HR, Ziaee T, Danaee A (2005): Protective effect of aqueous saffron extract (Crocus sativus L.) and crocin, its active constituent, on renal ischemia-reperfusion-induced oxidative damage in rats. J Pharm Pharm Sci 8, 387-93

Iliskovic N, Singal PK (1997): Lipid lowering: an important factor in preventing adriamycin-induced heart failure. The American journal of pathology 150, 727 
Konoshima T, Takasaki M, Tokuda H, Morimoto S, Tanaka H, Kawata E, Xuan L, Saito H, Sugiura M, Molnar J (1998): Crocin and crocetin derivatives inhibit skin tumour promotion in mice. Phytotherapy Research: An International Journal Devoted to Pharmacological and Toxicological Evaluation of Natural Product Derivatives 12, 400-404

Li DL, Wang ZV, Ding G, Tan W, Luo X, Criollo A, Xie M, Jiang N, May H, Kyrychenko V (2016): Doxorubicin blocks cardiomyocyte autophagic flux by inhibiting lysosome acidification. Circulation 133, 1668-1687

Li J, Lei H-t, Cao L, Mi Y-N, Li S, Cao Y-X (2018): Crocin alleviates coronary atherosclerosis via inhibiting lipid synthesis and inducing M2 macrophage polarization. International immunopharmacology 55, 120127

Liang Y, Zheng B, Li J, Shi J, Chu L, Han X, Chu X, Zhang X, Zhang J (2020): Crocin ameliorates arsenic trioxide-induced cardiotoxicity via Keap1-Nrf2/HO-1 pathway: Reducing oxidative stress, inflammation, and apoptosis. Biomedicine \& Pharmacotherapy 131, 110713

Ma T, Kandhare AD, Mukherjee-Kandhare AA, Bodhankar SL (2019): Fisetin, a plant flavonoid ameliorates doxorubicin-induced cardiotoxicity in experimental rats: the decisive role of caspase-3, COX-II, cTn-I, iNOs and TNF-a. Molecular biology reports 46, 105-118

Migrino RQ, Aggarwal D, Konorev E, Brahmbhatt T, Bright M, Kalyanaraman B (2008): Early detection of doxorubicin cardiomyopathy using two-dimensional strain echocardiography. Ultrasound in medicine \& biology 34, 208-214

Mousavi SH, Tayarani N, Parsaee H (2010): Protective effect of saffron extract and crocin on reactive oxygen species-mediated high glucose-induced toxicity in PC12 cells. Cellular and molecular neurobiology 30, 185-191

Octavia Y, Tocchetti CG, Gabrielson KL, Janssens S, Crijns HJ, Moens AL (2012): Doxorubicin-induced cardiomyopathy: from molecular mechanisms to therapeutic strategies. Journal of molecular and cellular cardiology 52, 1213-1225

Ohkawa H, Ohishi N, Yagi K (1979): Assay for lipid peroxides in animal tissues by thiobarbituric acid reaction. Analytical biochemistry 95, 351-358

Oner Z, Altınoz E, Elbe H, Ekinci N (2019): The protective and therapeutic effects of linalool against doxorubicin-induced cardiotoxicity in Wistar albino rats. Human \& experimental toxicology $38,803-813$

Pham TQ, Cormier F, Farnworth E, Tong VH, Van Calsteren M-R (2000): Antioxidant properties of crocin from Gardenia jasminoides Ellis and study of the reactions of crocin with linoleic acid and crocin with oxygen. Journal of Agricultural and Food Chemistry 48, 1455-1461

Qi W, Boliang W, Xiaoxi T, Guoqiang F, Jianbo X, Gang W (2020): Cardamonin protects against doxorubicin-induced cardiotoxicity in mice by restraining oxidative stress and inflammation associated 
with Nrf2 signaling. Biomedicine \& Pharmacotherapy 122, 109547

Rahaiee S, Moini S, Hashemi M, Shojaosadati SA (2015): Evaluation of antioxidant activities of bioactive compounds and various extracts obtained from saffron (Crocus sativus L.): a review. Journal of Food Science and Technology 52, 1881-1888

Razavi BM, Hosseinzadeh H, Movassaghi AR, Imenshahidi M, Abnous K (2013): Protective effect of crocin on diazinon induced cardiotoxicity in rats in subchronic exposure. Chemico-biological interactions $203,547-555$

Razmaraii N, Babaei H, Nayebi AM, Asadnasab G, Helan JA, Azarmi Y (2016a): Cardioprotective effect of phenytoin on doxorubicin-induced cardiac toxicity in a rat model. Journal of cardiovascular pharmacology 67, 237-245

Razmaraii N, Babaei H, Nayebi AM, Assadnassab G, Helan JA, Azarmi Y (2016b): Crocin treatment prevents doxorubicin-induced cardiotoxicity in rats. Life sciences $157,145-151$

Razmaraii N, Babaei H, Nayebi AM, Assadnassab G, Helan JA, Azarmi Y (2016c): Cardioprotective effect of grape seed extract on chronic doxorubicin-induced cardiac toxicity in Wistar rats. Advanced pharmaceutical bulletin 6,423

Sadek KM, Mahmoud SF, Zeweil MF, Abouzed TK (2021): Proanthocyanidin alleviates doxorubicininduced cardiac injury by inhibiting NF-kB pathway and modulating oxidative stress, cell cycle, and fibrogenesis. Journal of Biochemical and Molecular Toxicology, e22716

Shaker RA, Abboud SH, Assad HC, Hadi N (2018): Enoxaparin attenuates doxorubicin induced cardiotoxicity in rats via interfering with oxidative stress, inflammation and apoptosis. BMC Pharmacology and Toxicology 19, 1-10

Shen X-C, Qian Z-Y (2006): Effects of crocetin on antioxidant enzymatic activities in cardiac hypertrophy induced by norepinephrine in rats. Die Pharmazie-An International Journal of Pharmaceutical Sciences $61,348-352$

Songbo M, Lang H, Xinyong C, Bin X, Ping Z, Liang S (2019): Oxidative stress injury in doxorubicininduced cardiotoxicity. Toxicology letters $307,41-48$

Sun Y, Oberley LW, Li Y (1988): A simple method for clinical assay of superoxide dismutase. Clinical chemistry $34,497-500$

Sun Z, Yan B, Yu WY, Yao X, Ma X, Sheng G, Ma Q (2016): Vitexin attenuates acute doxorubicin cardiotoxicity in rats via the suppression of oxidative stress, inflammation and apoptosis and the activation of FOXO3a. Experimental and therapeutic medicine 12, 1879-1884 
Swain SM, Whaley FS, Ewer MS (2003): Congestive heart failure in patients treated with doxorubicin: a retrospective analysis of three trials. Cancer: Interdisciplinary International Journal of the American Cancer Society 97, 2869-2879

Takemura G, Fujiwara H (2007): Doxorubicin-induced cardiomyopathy: from the cardiotoxic mechanisms to management. Progress in cardiovascular diseases 49, 330-352

Takemura G, Kanoh M, Minatoguchi S, Fujiwara H (2013): Cardiomyocyte apoptosis in the failing heart-a critical review from definition and classification of cell death. International journal of cardiology 167 , 2373-2386

Tarr A, Stoebe S, Tuennemann J, Baka Z, Pfeiffer D, Varga A, Hagendorff A (2015): Early detection of cardiotoxicity by $2 \mathrm{D}$ and $3 \mathrm{D}$ deformation imaging in patients receiving chemotherapy. Echo research and practice $2,81-88$

Tavakkol-Afshari J, Brook A, Mousavi SH (2008): Study of cytotoxic and apoptogenic properties of saffron extract in human cancer cell lines. Food and Chemical Toxicology 46, 3443-3447

Thushara R, Hemshekhar M, Santhosh MS, Jnaneshwari S, Nayaka S, Naveen S, Kemparaju K, Girish K (2013): Crocin, a dietary additive protects platelets from oxidative stress-induced apoptosis and inhibits platelet aggregation. Molecular and cellular biochemistry 373, 73-83

Wu Y, Pan R-R, Geng P (2010): The effect of Crocin against hypoxia damage of myocardial cell and its mechanism. Zhongguo ying yong sheng li xue za zhi= Zhongguo yingyong shenglixue zazhi= Chinese journal of applied physiology $26,453-457$

Zamorano JL, Lancellotti P, Rodriguez Muñoz D, Aboyans V, Asteggiano R, Galderisi M, Habib G, Lenihan DJ, Lip GY, Lyon AR (2016): 2016 ESC Position Paper on cancer treatments and cardiovascular toxicity developed under the auspices of the ESC Committee for Practice Guidelines: The Task Force for cancer treatments and cardiovascular toxicity of the European Society of Cardiology (ESC). European heart journal 37, 2768-2801

Zhou S, Palmeira CM, Wallace KB (2001a): Doxorubicin-induced persistent oxidative stress to cardiac myocytes. Toxicology letters 121, 151-157

Zhou S, Starkov A, Froberg MK, Leino RL, Wallace KB (2001b): Cumulative and irreversible cardiac mitochondrial dysfunction induced by doxorubicin. Cancer research $61,771-777$

\section{Figures}




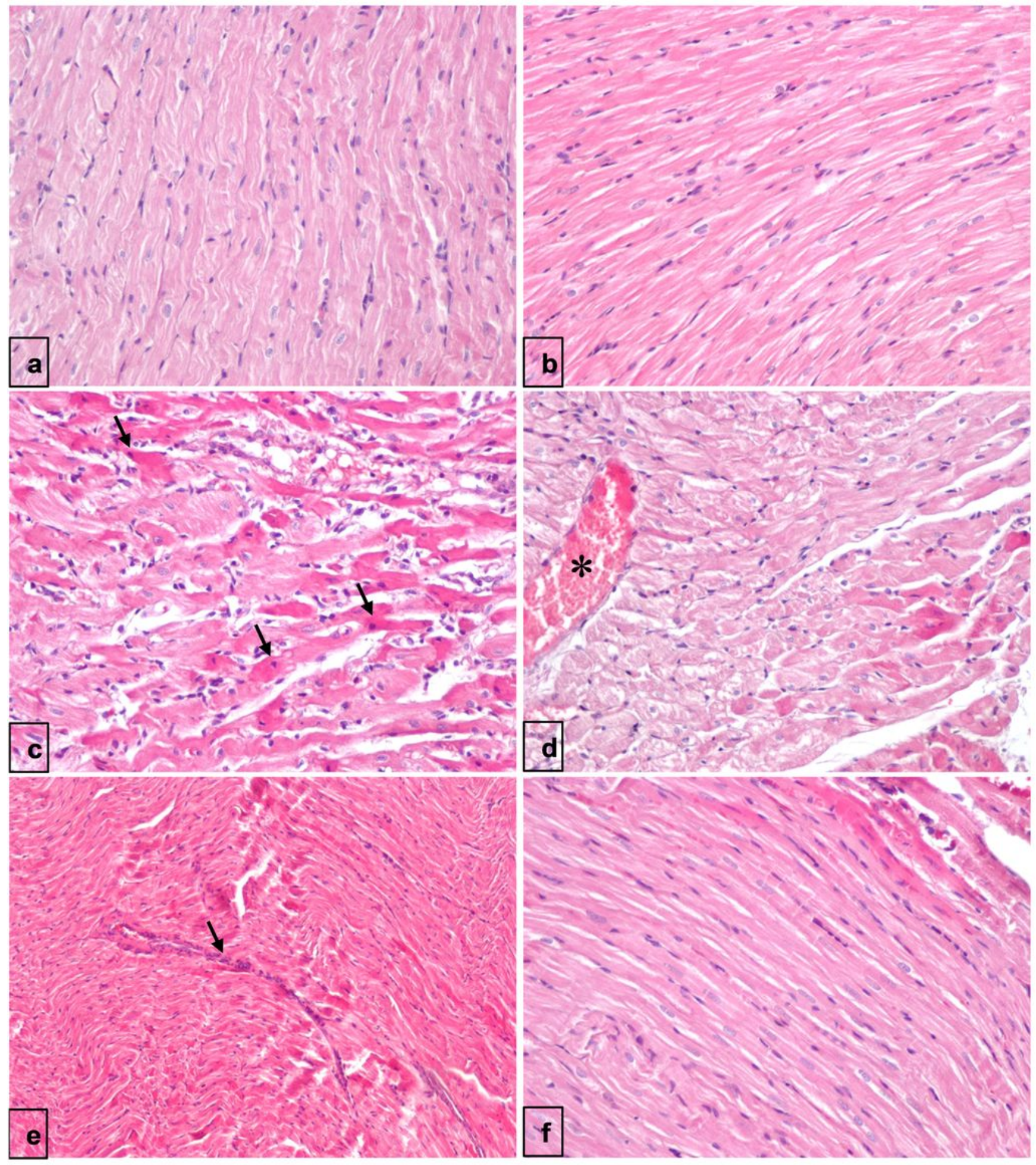

\section{Figure 1}

Photomicrograph showing histopathology of heart tissue. The control and crocin groups were normal in histological appearance. a. Control group, H-E; X20. b. Crocin group, H-E; X20. DOX group showed cardiac damage including (c) necrotic cells with picnotic nuclei (arrows), (d) congestion (asterisk), loss of myofibrillar and, cytoplasmic vacuolization (e) inflammatory cells infiltration (arrow). c. DOX group, H-E; 
X20. d. DOX group, H-E; X20. e. DOX group, H-E; X10. The histopathological changes markedly regressed in the DOX+Crocin group. f. DOX+Crocin group, H-E; X2O.

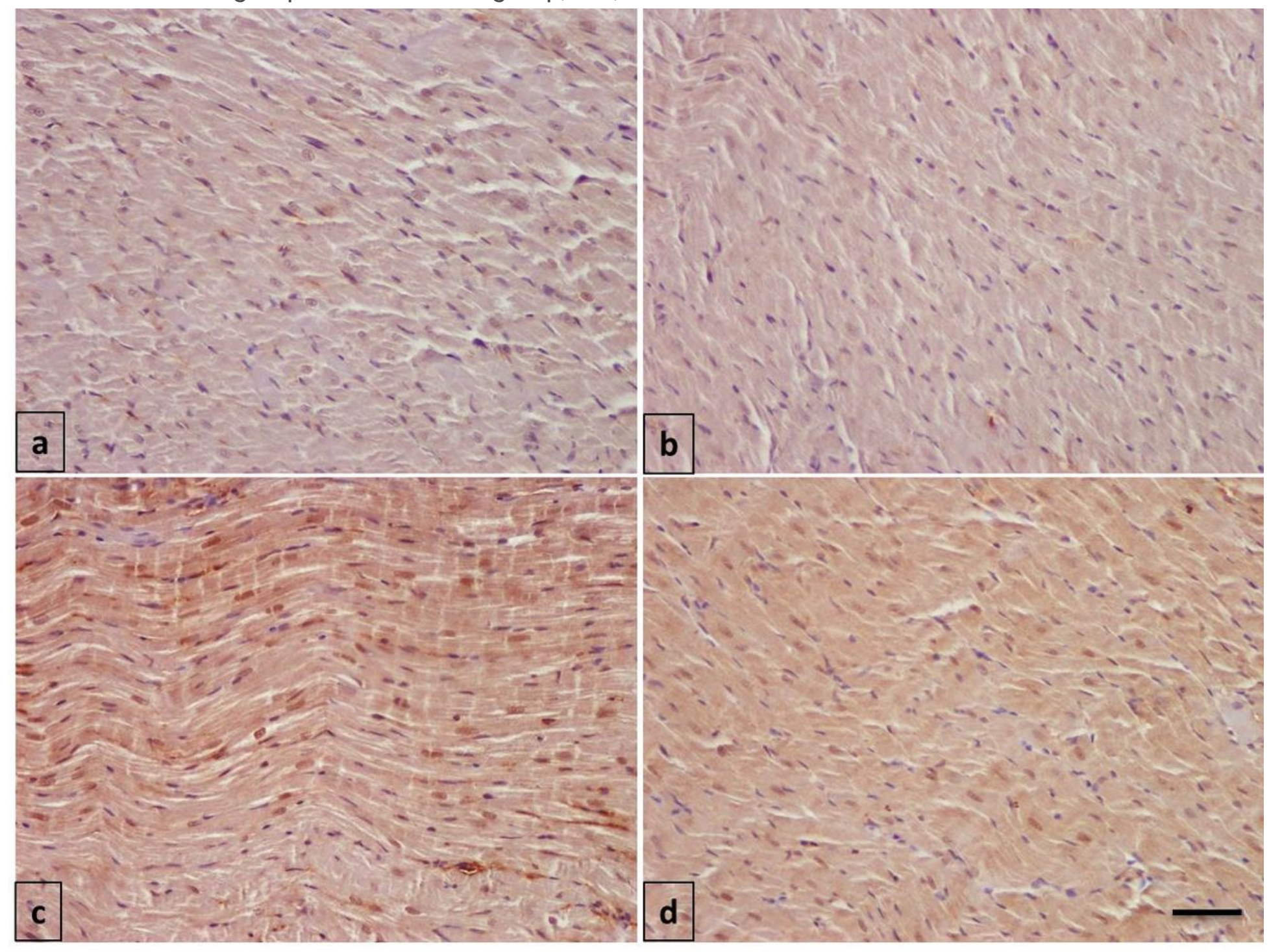

\section{Figure 2}

TNF-a immunoreactivity in the heart tissue. Control and Crocin groups were similar. In the DOX group, apoptosis was most evident. The intensity of TNF-a was reduced in DOX+Crocin group. a. Control group, b. Crocin group, c. DOX group, d. DOX+Crocin group; X20. 


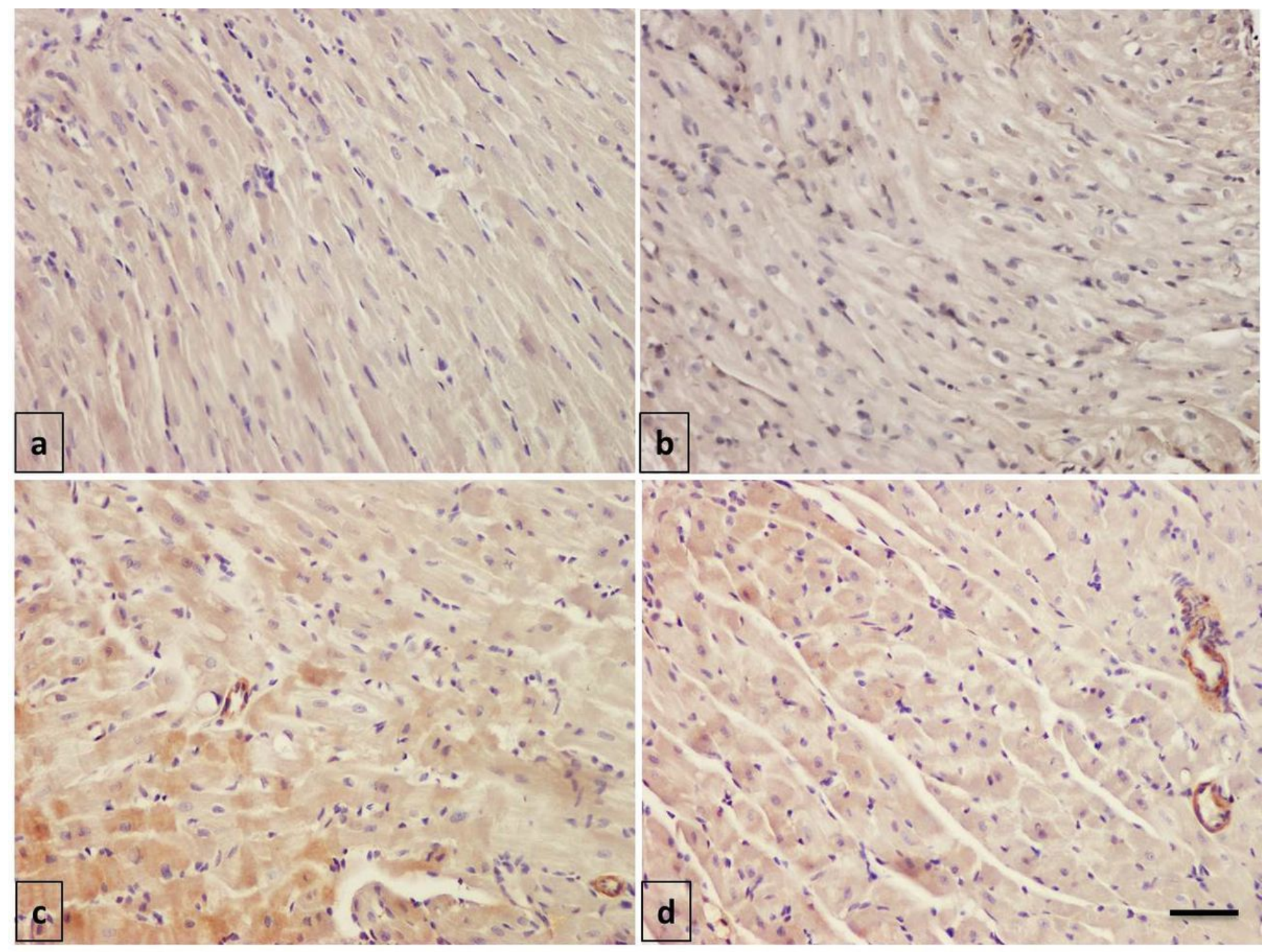

Figure 3

Caspase-3 immunoreactivity in the heart tissue. Control and Crocin groups were similar. In the DOX group, apoptosis was most evident. The intensity of caspase- 3 was reduced in DOX+Crocin group. a. Control group, b. Crocin group, c. DOX group, d. DOX+Crocin group; X20. 